\title{
Knowledge Of And Attitude Towards Reproductive Health Among Female Adolescence (Aged 15-19 Years): A Study Of Lower Hunza
}

\author{
Kaneez Fatima Mamdan, Munazza Madani \\ Department of Sociology \\ University of Karachi \\ \& \\ Sultana Shaheen \\ Department of Population Sciences \\ University of Karachi
}

\begin{abstract}
The reproductive health of adolescents is of growing concern all over the world. At the global level, many young people get involved in sexual activities and risk sexually transmitted infections (STIs), including HIV or involvement in unintended pregnancy. Young people every where reach puberty earlier and marry later than in the past. As a result, youth are sexually mature for a longer period of time prior marriage. Adolescent pregnancy and childbearing is a major concern and is associated with a range of outcomes detrimental to teen's health, including complications of pregnancy, illegal and unsafe abortions and death, especially in less developed nations. Fifteen million women age 15-19, give birth every year, 13 million belonging to less developed countries. Over all, 33 percent women from less developed countries give birth before the age of 20 -varying from 8 percent in East Asia to 55 percent in West Africa- (UNFPA; 2000).

Adolescent girls in many South Asian settings are unlikely to have much exposure or physical access to outside world. Few services cater to their needs for health care, nutrition, vocational skills, economic opportunities or information. Sizeable proportions of women in south Asia marry well before 18, and early pregnancy further exacerbates their poor reproductive health. This paper examines the knowledge and attitude of female adolescence aged 15-19 years about their reproductive health in Lower Hunza, Northern Areas of Pakistan. First part of this paper comprises introduction of adolescence and reproductive health, its worldwide and Pakistani situation. The second part of the paper consists of hypotheses and key concepts of the study and the third comprises methodology and statistical analysis of the hypotheses. The last section consists of conclusions and recommendation for the improvement of knowledge and awareness programmes for female adolescents as they are more vulnerable than male.
\end{abstract}

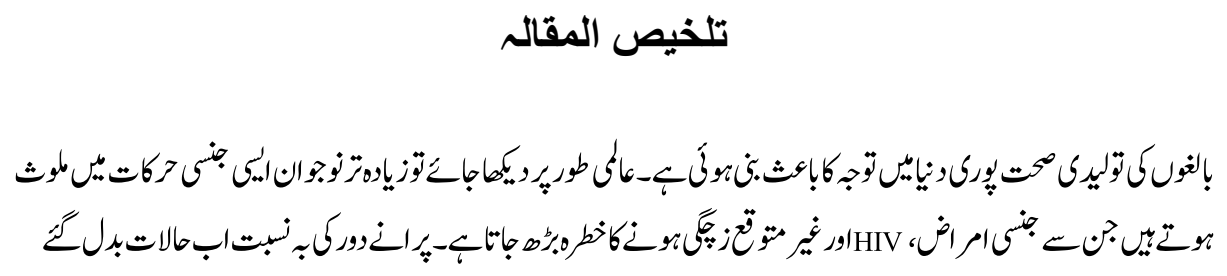




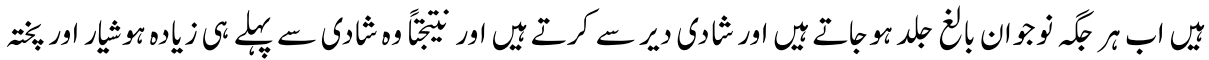

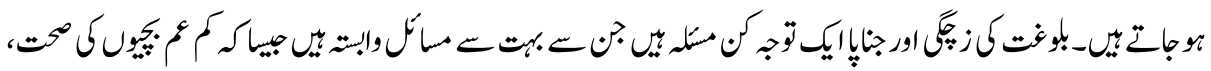

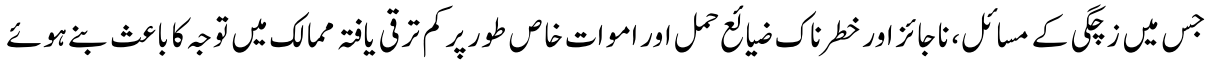

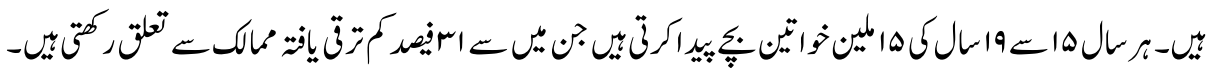

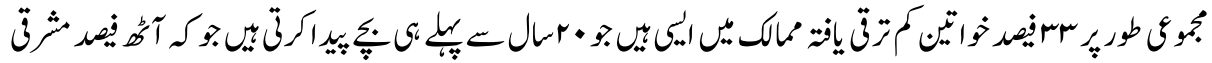

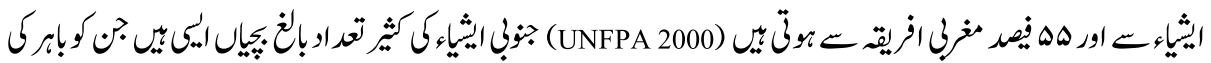

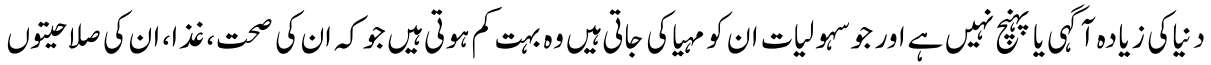

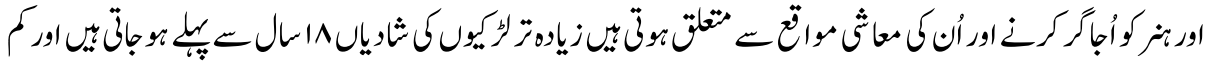

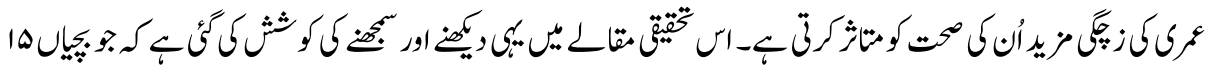

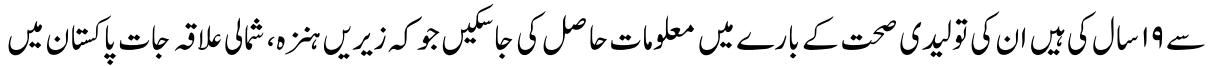

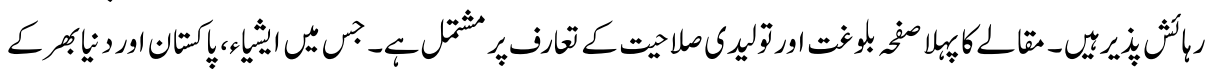

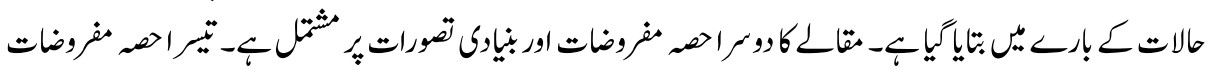

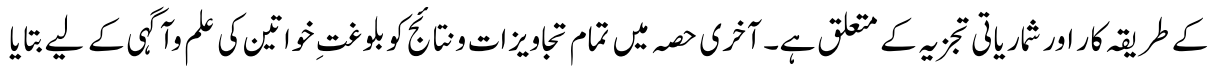

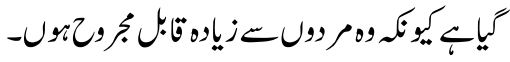

\section{Introduction}

One billion adolescents are about to enter their reproductive years. For all of them it will be a critical time for many it will be fatal. Over five women die in pregnancy and child birth every year, many of them are young girls; today forty two million people are living with HIV aids. Half of all new HIV infections are among young people. Specially girls are at particular risk. At the International Parliamentarians Conference (IPC / ICPD) in Ottawa, Canada, elected representatives from seventy two countries and territories pledged to save adolescent lives by giving them education, opportunities and services that are vital for their health. (IPC / ICPD and UNFPA).

The term adolescent refers to people between the ages of $10-19$, "youth" is defined as people between $15-24$ years of age, and "young people" between $10-24$ years, while the old make up distinct yet overlapping categories (WHO/UNICEF/UNFPA: 1998; 7-8). Today the world is a home to the largest generation of 10 to 19 years old in history, the number is over one billion and it is increasing (Allan Guttmacher Institute: 1998; 1). One out of five in the world is an adolescent. The reproductive health needs of this group for the most part have been either ignored or neglected by the governments and societies or adolescent health has been treated as indistinguishable from childhood health (CRLP: $2000 ; 57)$. The nature of adolescent varies tremendously by age, sex, marital status, class, region and cultural context as a group and adolescents have sexual and reproductive health needs that from those of adults in important ways and which remains poorly 
understood. Moreover, social, economic and political forces are rapidly changing the ways that young people must prepare for adult life. These changes have enormous implications for adolescents' education, employment, marriage, child bearing and health. (Bott; Jejeebhoy: 2003)

\section{Reproductive Health of Adolescents World Wide}

The world is facing the largest generation of adolescents in the history of mankind. Currently one in every fifth is an adolescent between 10-19 years (Nehar et al: 1999). There were 1.21 billion adolescents in the world in 2005. Population in this age group is estimated to continue to increase and would finally reach 1.23 billion by the year 2040 (UN: 2005). Of the World's 1.21 billion adolescents, 913 million or $85 \%$ live in developing countries. $49 \%$ of them are female. Out of these 1.1 billion, 160 million live in the developed world. This will be the largest generation in the history to make the tradition from child to adulthood. The sheer size of this group commands attention. (WHO: 1995-97-98)

The broad definition of reproductive health agreed on by the international community including Pakistan, at the 1994 International conference on population and development is that "Reproductive health is a state of complete physical, mental and social well being and merely absence of disease or infirmity, in all matters relating to the reproductive system and to its functions and its processes reproductive health therefore implies that people are able to have a satisfying \& safe sex life and that they have the capability to reproduce and the freedom to decide if, when and how often to do so. Men and women have the right to be informed and have access to safe, effective, affordable, acceptable methods of their choice for the regulation of fertility, as well as access to health care for safe pregnancy and child birth. (Alcla: 1994; 10)

Factors effecting reproductive health include:

- Normal body weight: weighting too much or too little can put health at risk and can diminish fertility;

- Exercise is another factor playing an important positive role during reproductive years of life and is also helpful in having balanced weight;

- Unprotected sex is a crucial factor of reproductive health. It can lead to HIV/AIDS and sexually transmitted diseases.

- Another factor is pregnancy during 15-19 years of reproductive health. This is very dangerous and has the high risk of maternal deaths, abortion and infections (Khan R.R: 2006; 9-10). 


\section{Status of Adolescents Reproductive Health in Pakistan}

The reproductive health status of adolescents has acquired increased attention in Pakistan in the recent years. There are about 30 million adolescents $(15-19)$ which constitutes $23 \%$ of Pakistan's population. Those aged $10-24$ years are 42 million and comprise almost a quarter of total population (PCO: 1998). This is an important target group for sensitization of reproductive health issues. The adolescents, who are at a stage of forming their habits and values, are about to enter their reproductive years of life and are strongly influenced by pears, are at great risk of unsafe sexual and social behavior which may put them at increased risk of HIV infection and other reproductive health problems (Chaudhary \& Mir: 2004; 243-244). Adolescent marriage particularly among girls is still common in Pakistan. In the age group $15-19$ years, $17 \%$ of females get married, while in the age category of $20-24$, about $54 \%$ of females get married. These proportions are higher for rural women (42\% under 19). The recently conducted national level survey on adolescent and youth in Pakistan provides some indicators on teenage motherhood, reproductive physiology and related problems of youth in Pakistan. (Population Council: 2003). One such survey provides information about mothers' discussion with their daughters regarding reproductive health in Pakistan.

\section{Table 1}

Mothers Discussing With And Educating Their daughters About Reproductive Health And Reasons For Out Discussing (\%)

\begin{tabular}{|l|c|c|c|c|c|c|}
\hline $\begin{array}{c}\text { Residence/ } \\
\text { Province }\end{array}$ & $\begin{array}{c}\text { Discussed } \\
\text { adolescent RH } \\
\text { problems }\end{array}$ & $\begin{array}{c}\text { Educating } \\
\text { adolescents } \\
\text { not } \\
\text { Important }\end{array}$ & Shyness & $\begin{array}{c}\text { Reason } \\
\text { indecent/ } \\
\text { culturally } \\
\text { intolerable }\end{array}$ & $\begin{array}{c}\text { Daughters will } \\
\text { do herself }\end{array}$ & Others \\
\hline All Women & 37.6 & 56.8 & 31.0 & 19.9 & 32.9 & 18.2 \\
\hline Urban & 46.1 & 45.3 & 28.0 & 19.5 & 30.7 & 21.7 \\
\hline Rural & 32.8 & 62.0 & 32.0 & 20.0 & 33.6 & 15.8 \\
\hline Punjab & 40.5 & 54.3 & 32.1 & 16.9 & 30.9 & 20.0 \\
\hline Sindh & 43.0 & 61.8 & 24.8 & 19.8 & 40.7 & 14.8 \\
\hline NWFP & 20.0 & 60.0 & 35.8 & 31.2 & 26.2 & 7.0 \\
\hline Balochistan & 39.0 & 47.0 & 45.4 & 17.7 & 27.7 & 9.3 \\
\hline
\end{tabular}

Source: PRHFPS $2000-2001$

The above table indicates that Pakistan Reproductive Health and Family Planning surveys (PRHFPS) of 2000 - 01 do provide insight into the reproductive health related issues of adolescents. The findings show that about $38 \%$ of mothers reported to have discussed reproductive health problem faced with their daughters, when they had attained puberty. About 57\% women did not consider it important to educate their daughters about body and emotional changes and these proportions vary by the background and level of education of mothers. 


\section{Operational Barriers to Adolescents Reproductive Health in Pakistan}

The operational barriers to adolescent reproductive health in Pakistan are: a) Limited information available to adolescents; b) Inability to obtain services.

Many adolescents in South Asia are poorly informed about sexual issues and reproductive health. Any information received is often incomplete and confused. Low levels of school attendance, lack of sex education and attitudes prohibiting discussion of sexual issues all confound to exacerbate ignorance on these matters (MC Cauley \& Salter: 1995 and Boot Sara \& Jejeehoy: 2002). Parents also experience difficulties in communicating with adolescents about sexual issues and may provide only limited or vague information. The Pakistan education system includes population, family planning and reproductive biology modules but there is no formal curriculum for sex education, which remains a taboo subject. The tacit assumption among adults and policy makers, as well as health and family planning service providers, seems to be that young people will get whatever information they need when it is proper - that is, when they are married. In fact community and school-based programs have encountered resistance to sexual and reproductive health training among adolescent, particularly due to lack of information sources, government policies that restrict sex education in curriculum, school authorities, teachers and parents (Javeed: 2003, Lal: 2002 \& Masood: 1999).

Even the issue of adolescent sexuality has become a sticking point in international debate on population policies. The stand off is between two perspectives. One view is that providing adolescents with information about their sexuality and, especially, with reproductive health services will encourage early sexual activity and promiscuity. The opposite view holds that young people need information about their changing bodies and the implications of sexual activity in order to make more responsible and healthconscious decisions (Ashford, 1995; 24). The reality of adolescents Life which includes sexual abuse and rape, misconceptions and anxieties about their developing sexuality, lack of information about the other sex, pregnancy risks, and STIs is being denied out of fear that information will lead to an increase in premarital sex. As a result, even adolescents who are married and in need of sex education have no access to neutral information to protect their health and improve their sexual relations. (Khan: 1998, Mumtaz \& Raouf: 1997)

\section{Situation of Health in Lower Hunza, Northen Areas}

The Northern Areas of Pakistan are spread over 72,496 square kilometers with a population of about one million people. The subdivision Hunza consists of two main regions; Upper Hunza and Lower Hunza. Lower Hunza administratively consists of Tehsil Ali Abad, and it is situated in district Gilgit. Karimabad is the capital of Hunza. Lower Hunza is an agrarian society and economy is based on agriculture, tourism and trade. The women play an important role in the fields and the people of the area are 
peace-loving and simple in nature. The total population of Hunza, age and sex of adolescents in age group 15 -19 in Hunza sub-division is given in the following table.

Table 2

Population by Single Age Year from 15 - 19 by Sex in Hunza Sub-Division

\begin{tabular}{|l|c|c|c|}
\hline \multirow{2}{*}{ Age (in years) } & \multicolumn{2}{|c|}{ Sex } & \multirow{2}{*}{ Total } \\
\cline { 2 - 3 } & Male & Female & 46784 \\
\hline All Ages & 24040 & 22744 & 1192 \\
\hline $\mathbf{1 5}$ & 580 & 612 & 995 \\
\hline $\mathbf{1 6}$ & 468 & 527 & 874 \\
\hline $\mathbf{1 7}$ & 461 & 413 & 1324 \\
\hline $\mathbf{1 8}$ & 656 & 668 & 906 \\
\hline $\mathbf{1 9}$ & 431 & 475 & 5291 \\
\hline $\mathbf{1 5}-\mathbf{1 9}$ & 2596 & 2695 & \\
\hline
\end{tabular}

Source: Statistical tables of 1998 population census

The Northern part of Pakistan is different from the country as climate is extreme and for several months of the year, it is harsh and barren with temperatures frequently below freezing. Female trained health professionals available to offer health services in the Northern Areas are very few and it may be attributed to as one of the main reasons for high rate of maternal deaths, because it is part of the culture that women can seek advice only from females. There is little knowledge about basic nutrition, and balanced intake of food, and the situation is exacerbated by cultural backlash, religious taboos and traditional habits.

Lower Hunza, like other Northern areas, with limited health facilities is trying to meet the needs of the people, but the coverage in far-flung areas is low because of dilapidated infrastructure, poor communication and limited funds. The major spending on health results in weak infrastructure and lack of trained health professionals especially in the far flung areas. Most of the population does not have access to health facilities. In the Northern areas and Chitral, immunization of children and pregnant women is a joint venture of govt. health department and AKHSP. Such joint ventures between the public and private sectors need to be strengthened if the dream of providing accessible, affordable and quality health services to every citizen of Pakistan is to be realized.

Before moving further and highlighting the level of knowledge or lack of it and prevalent attitude towards reproductive health among female adolescents in lower Hunza, it is important that the research methodology applied in this paper is explained and the key concepts discussed. 


\section{Research Methodology}

The nature of present study is based on quantitative methodology. This study is exploratory because of the nature of the problem. Two different probability-sampling methods have been used for the selection of area and data collection. The simple random sampling and systematic random sampling have been used to conduct the present research. The sub-division of Hunza consists of two portions of the Lower and Upper Hunza. Through lottery, method of simple random sampling Lower Hunza was selected and the researchers took information from late female adolescents belonging to different villages of Lower Hunza. Systematic Sampling method was used by the researchers to collect data from the adolescences. 135 respondents were taken as sample size $(10 \%)$ of total households, but at the end, the sample size remained 110 , as twenty five questionnaires were not included because of non response by the respondents. Interview schedule was used as a tool to collect the data. Coded data was transferred in SPSS 14.0 version and was also used to construct simple tables. Chi-square tests and Co-efficient of Correlation had been used in the study to analyze the data and hypotheses with the help of SPSS (Statistical package for social science).

Key Concepts: The following are the key concepts used in research for present study:

Age: Age referred to: how old was the adolescent? Lower age (15-16) and higher age (17-19)

Adolescence Educational Status: The educational level of adolescents and the variable was divided into two categories; Low level represents educational level of adolescent up to class 8th and High level refers to educational level of adolescents more than class 8 .

Family Type: It refers to the type of family in which adolescents were living either in joint or nuclear families.

Educational Status of Mother: It meant whether mother went to school or any institution to get education or not. It was divided into two categories: Literate (it means mother has received formal education), and Illiterate (it means mother has no formal education)

Knowledge about Sexually Transmitted Disease: It refers to the knowledge of adolescents about sexually transmitted infections. This variable was divided into: Having knowledge (Yes, to some extent), and No knowledge (no)

Main Source of Information following First Menstruation: It refers to the main source of information about puberty for adolescents. And mother is considered as the main source of information. This variable was operationalized into following categories; Mother, and Others (sister, friends)

Number of Children in Family: This refers to the total number of children in family. It was divided into; Less Children (1-6 children), and More children (seven and above). 
Discussion on sexual intercourse: It referred to discussion about sexual intercourse. It was also divided into two categories; discussed (yes, to some extent) and not discussed (no)

Discussion on Contraceptives Use: It is about discussion with adolescents about use of contraceptives. The variable was operationalized into: discussed (yes, to some extent) and not discussed (no)

Table 3

Educational Status of Adolescents and Knowledge About Sexually Transmitted Infections

\begin{tabular}{|l|c|c|c|}
\hline \multirow{2}{*}{$\begin{array}{c}\text { Knowledge About Sexually } \\
\text { Transmitted Infections }\end{array}$} & \multicolumn{2}{|c|}{ Adolescents Educational Status } & \multirow{2}{*}{ Total } \\
\cline { 2 - 3 } & $\begin{array}{c}\text { Low level ( up to } \\
\text { middle) }\end{array}$ & $\begin{array}{c}\text { High level Metric } \\
\text { \&above }\end{array}$ & \\
\hline Having knowledge & $8(4)$ & $12(16)$ & 20 \\
\hline No Knowledge & $14(18)$ & $76(72)$ & 90 \\
\hline Total & 22 & 88 & 110 \\
\hline
\end{tabular}

Calculated value of Chi-square $=6.1$

Coefficient of correlation $=0.2354$

$\mathrm{H}_{\mathrm{o}}=$ There is no relationship between educational status of adolescents and knowledge about sexually transmitted infections.

$\mathrm{H}_{1}=$ There is relationship between educational status of adolescents and knowledge about sexually transmitted infections.

As the calculated value of Chi-square is greater than its table value, the null hypothesis is rejected and alternate hypothesis is accepted and it is concluded that both adolescent's educational status and knowledge about sexually transmitted infections are related. According to the result the higher the educational status of adolescents, higher will be the knowledge about STIS and vice versa, therefore, coefficient of contingency is 0.2354 , showing weak degree of association.

Table 4

Mother as Main Source of Advice Following First Menstruation and Family Type

\begin{tabular}{|l|c|c|c|}
\hline \multirow{2}{*}{$\begin{array}{c}\text { Mother as Main Source of } \\
\text { Information Following First } \\
\text { Menstruation }\end{array}$} & \multicolumn{2}{|c|}{ Family type } & \multirow{2}{*}{ Total } \\
\cline { 2 - 3 } & Joint & Nuclear & \\
\hline Mothers & $15(21.45)$ & $44(37.54)$ & 59 \\
\hline No Knowledge & $25(18.54)$ & $26(32.45)$ & 51 \\
\hline Total & 40 & 70 & 110 \\
\hline
\end{tabular}

Calculated value of Chi-square $=6.1$

Coefficient of correlation $=0.2413$ 
$\mathrm{H}_{\mathrm{o}}=$ There is no relationship between mother as main source of information following first menstruation and nuclear families

$\mathrm{H}_{1}=$ There is relationship between mother as main source of information following first menstruation and nuclear families.

Since the calculated value of Chi-square is greater than its table value, it is concluded that family type and main source of information about puberty are interrelated.

Mother is the main source of information following first menstruation in nuclear families in adolescent girls. In view of statistical analysis, coefficient of contingency shows weak degree of association.

\section{Table 5}

\section{Educational Status of Mother and Number of Children in Family}

\begin{tabular}{|l|l|l|l|}
\hline \multirow{2}{*}{\multicolumn{1}{c|}{ No of Children in Family }} & \multicolumn{2}{c|}{ Educational Status of Mother } & \multirow{2}{*}{ Total } \\
\cline { 2 - 3 } & \multicolumn{1}{|c|}{ Illiterate } & \multicolumn{1}{c|}{ Literate } & \multicolumn{1}{c}{} \\
\hline Less children & $7(25.52)$ & $32(13.44)$ & 39 \\
\hline No Knowledge & $65(46.47)$ & $6(24.52)$ & 71 \\
\hline Total & 72 & 38 & 110 \\
\hline
\end{tabular}

Calculated value of Chi-square $=60.29$

Co efficient of correlation $=0.740$

$\mathrm{H}_{\mathrm{o}}=$ There is no relationship between educational status of mother and number of children in family

$\mathrm{H}_{1}=$ There is relationship between educational status of mother and number of children in family.

As the calculated value of Chi-square is greater than its table value, it is concluded that there is relationship between educational status of mother and number of children in family. According to the result there is relation ship between two variables therefore, coefficient of contingency is 0.740 , showing strong degree of association.

\section{Table 6}

\section{Age and Discussion Sexual Intercourse}

$\mathrm{H}_{\mathrm{o}}=$ There is no relationship between age and discussion on sexual intercourse.

$\mathrm{H}_{1}=$ There is relationship between age and discussion on sexual intercourse.

\begin{tabular}{|l|c|c|c|}
\hline \multirow{2}{*}{ Discussion on Sexual Intercourse } & \multicolumn{2}{|c|}{ Age } & \multirow{2}{*}{ Total } \\
\cline { 2 - 3 } & Low age & High age & \\
\hline Discussed & $42(39.2)$ & $12(16.8)$ & 54 \\
\hline No Knowledge & $35(37.8)$ & $21(16.2)$ & 56 \\
\hline Total & 77 & 33 & 110 \\
\hline
\end{tabular}

Calculated value of Chi-square $=6.1$

Co efficient of correlation $=0.23$ 
The calculated value of Chi-square is greater than its table value, thus it is concluded that there is relationship between age and discussion on sexual intercourse. Coefficient of contingency shows weak relationship between age and discussion about sexual intercourse.

Table 7

Adolescents Educational Status and Discussion on Contraceptive Use

\begin{tabular}{|l|c|c|c|}
\hline \multirow{2}{*}{ Discussion about Contraceptive } & \multicolumn{2}{|c|}{ Educational Status of Adolescents } & \multirow{2}{*}{ Total } \\
\cline { 2 - 3 } & Low level & High level & \\
\hline Not Discussed & $7(10.2)$ & $44(47.2)$ & 51 \\
\hline Discussed & $15(11.8)$ & $44(40.8)$ & 59 \\
\hline Total & 22 & 88 & 110 \\
\hline
\end{tabular}

Calculated value of Chi-square $=6.1$

Co efficient of correlation $=0.229$

Ho $=$ There is no relationship between adolescents educational status and discussion on contraceptive use.

$\mathrm{H} 1=$ There is relationship between adolescents educational status and discussion on contraceptive use.

The result shows relationship between educational level of adolescents and discussion on contraceptive use. Coefficient shows weak relationship between the variables.

The findings of the study reveal that the knowledge of late female adolescents in lower Hunza is not very much admirable, because adolescents still lack the knowledge about some aspects of reproductive health and some where their knowledge is based on misconceptions. It is observed from the findings of the study that majority of the respondents don't know the puberty, reproductive age of women, contraceptive use and mother was the main source of information following first menstruation and was considered the most important for educating adolescents about reproductive health. However, unfortunately majority of the mothers are illiterate and they themselves lack information about reproductive health, reproductive organs, normal physiology and dos and dons. Hence, they transfer limited knowledge to their daughters. The adolescents, knowledge is also based on misconceptions about reproductive health, as they consider masturbation harmful to health, but the review of medical literature reveals that it's not harmful to human's health. Another aspect is that these adolescents are well aware of societal norms and this is evident from the statement that adolescents agree that homosexual behavior and premarital sex is not allowed in the society.

\section{Recommendations}

- Adolescents must be thought and treated as a distinct segment of population with specific developmental needs. This understanding must be shared and discuss 
with public and non governmental institutions to work towards the development of a framework for adolescents reproductive health.

- Adolescents must be given access to reliable information on reproductive biology and sexuality through various programmatic interventions. Issues such as menstruation, and masturbation, and general sexuality are fraught with misconceptions and taboos. As a result, adolescents exhibit an anxiety level about their sexual development that is unhealthy and unnecessary.

- Print and electronic media can be utilized to address the reproductive health of adolescents.

- Provide information, education, and support to promote sexual and reproductive health of adolescents. Educating adolescents HIV / AIDS and sexually transmitted infections, puberty, sexual intercourse, reproductive biology will not encourage them to increase sexual activity, rather they will provide protection for them selves if they will be well aware of that.

Much more research needs to be done to be conducted on adolescent reproductive health related health topics including premarital sex.

\section{References}

Alan Guttmacher Institute (1998) In to a new world: young women sexual and reproductive lives, Alan Guttmacher Institute, New York

Alcla, Maria Jose. (1994) Action for 21st century RH and rights for all New York family center international.

Arain, Imran (2003) Knowledge, Attitude, and Practices Regarding Reproductive Health, Stopes Society (MSS), Karachi, Pakistan

Ashford, Lori S. (1995) Population Bulletin, New perspectives on population: lesson from Cairo, A Publication by Population Reference Bureau, Inc

Babbie, Earl. (2004) The practice of social research McGraw Hill book company INC, New York.

Baker, Therese L. (2001) Doing social research 3rd edition. Allah Walla printers Lahore, Pakistan

Bott S, Jejeebhoy S. (2003) "Adolescents sexual and reproductive health" in South Asia: An overview of findings from 2000 Mumbai conference. In: Bott S, Jeejeebhoy S, Shah I, Puri C. (eds) Towards adulthood: exploring the sexual and reproductive health of adolescents in South Asia. Geneva: World Health Organization, 

15-19 Years): A Study of Lower Hunza

Center for Reproductive Laws and Policies (CRLP), (1999) Adolescent Reproductive Rights: Laws and policies to improve their health and lives 1 here in after adolescents reproductive right

Chaudhry, Mohd A. and Mir, Ali Mohammad. (2004) "An Introduction to Medical Demography and Population Studies", Iftikhar Book Company. Rawalpindi, Pakistan

Durrant, Valerie L. (2000) Adolescent Girls in Pakistan: Opportunities and Constraints in the Transition to Adulthood. December, Research Report No.12. Islamabad: Population Council. Hakim, A. Mehhboob Sultan, and Faateh -Ud -Din. (2001).Pakistan Reproductive Health and family planning Survey, 2000-2001. Islam Abad: National Institute of Population Studies.(NIPS), Islamabad, Pakistan

Government of Pakistan, 2001.(1998) census report of Pakistan, Pakistan census organization, Statistics division, Islamabad, Pakistan

Javeed, Sarah (2003) Program approach assessment of MSS YANS and CANS program MSS Pakistan, Karachi, Pakistan

Khan, a. (2000). Adolescents and Reproductive Health in Pakistan: A literature Review. Research Report No 11. population Council and United Nations Population Fund (UNFPA), Islamabad, Pakistan

Khan, Ayesha. (2003) Adolescents and Youth Reproductive Health in Pakistan: status, issues, policies and programs

Lal, Khushi. (2002) Adolescent Sexual Education and Reproductive Health in Pakistan. Pp.149-155 in Body, Mind and Spirit in Sexual Health, National Conference Report. AAHUNG, Karachi, Pakistan

Masood, Shabeen Naz. (1999) "Sexual and Reproductive Health and Right", Advance International Training Programme Asia, Reports of Participants. 174-183

Ministry of Population Welfare. (2002) "Population Policy of Pakistan" Government of Pakistan, Islamabad, Pakistan

Mumtaz, Khawar and Fauzia Rauf. (1996) "Women to Women: Transfers of the Health and Reproductive Knowledge". Lahore: Shirkat Gah.

Nahar (etal) (1999) "Reproductive health need of adolescents in Bangladesh: A Study Report." Operations research project health and extension division ICDDR, b: Center for health and population research, Dhaka, Bangladesh 
Newman, W.Lawrence. (2006) "Social science research. Quantitative and qualitative approaches." 6th edition. Pearson Allyn and Bacon Publisher, USA

Pakistan reproductive health \& family planning surveys 2000-01. Preliminary report Islamabad

Pakistan reproductive health $\&$ family planning surveys $2000-2001$

Pakistan's Reproductive health service package .Ministry of health and Ministry of population welfare Government of Pakistan. Islamabad

Population council (2003) "Research on unwanted pregnancies in Pakistan" Interim Narrative Report, population Council Pakistan

Sarantakos, Sotirious. (1998) Social research, (2nd edition) Mac Million Press Limited Hound Mills Basing Hampshire, Australia

UNFPA, (1998) The Sexual and RH of adolescents technical report no 43, 7

UNICEF: (1999) State of the world children

United Nations Population Fund (UNFPA). (1998) Pakistan country paper. Paper Presented at the South Asia Conference on the Adolescent, New Delhi, India, 21 to 23 July 1998.

United Nations Population Fund (UNFPA). (2nd April 1998) "Technical and Policy Division Draft Report, The Sexual and Reproductive Health of Adolescents"

Weeks, John R. (2002). "Population: An Introduction to Concepts and Issues" (8th edition.) Wadsworth Group. Thomas learning, Latin America

WHO, "Adolescent health and development: the key to Geneva" Wortman Camille B. and Loftus, Elizabeth F (1988).University of Michigan and University of Washington, Alfred A. Knop, INC, New York

WHO. (1997) "Adolescence: the critical phase, the challenges and the potential" Regional office for South East India, New Delhi

WHO. (1998) "Towards 2010. The challenges for adolescent health and development" report of the meetings of the technical advisory group for the WHO adolescent health and development programme. Geneva March 25 to 26

World population prospects: 2000 The 2004 Revision .New York, United Nations, 


\section{Appendix}

Frequency and Percentage Distribution of Respondents According to Their Knowledge and Attitude About Reproductive Health

\begin{tabular}{|c|c|c|c|}
\hline Indicators & Frequency & Percent & Cumulative Percent \\
\hline \multicolumn{4}{|c|}{$\begin{array}{l}\text { I. Personal Profile } \\
\text { Age Group(In years) }\end{array}$} \\
\hline $15-16$ & 77 & 70.0 & 70.0 \\
\hline 17-18 & 6 & 5.5 & 75.5 \\
\hline 19 & 27 & 24.5 & 100.0 \\
\hline Total & 110 & 100.0 & \\
\hline \multicolumn{4}{|c|}{ Respondents educational (level) } \\
\hline Middle & 22 & 20.0 & 20.0 \\
\hline Matriculate & 67 & 60.9 & 80.9 \\
\hline Intermediate & 21 & 19.1 & 100.0 \\
\hline Total & 110 & 100.0 & \\
\hline \multicolumn{4}{|l|}{ Family type } \\
\hline Joint & 40 & 36.4 & 36.4 \\
\hline Nuclear & 70 & 63.6 & 100.0 \\
\hline Total & 110 & 100.0 & \\
\hline \multicolumn{4}{|c|}{ Number of family members } \\
\hline $1-4$ & 2 & 1.8 & 1.8 \\
\hline $5-8$ & 26 & 23.6 & 25.5 \\
\hline 9-11 & 30 & 27.3 & 52.7 \\
\hline 12 and above & 52 & 47.3 & 100.0 \\
\hline Total & 110 & 100.0 & \\
\hline \multicolumn{4}{|c|}{$\begin{array}{l}\text { II. Knowledge of Respondents } \\
\text { Puberty knowledge }\end{array}$} \\
\hline No & 64 & 58.2 & 58.2 \\
\hline Yes & 46 & 41.8 & 100.0 \\
\hline Total & 110 & 100.0 & \\
\hline \multicolumn{4}{|c|}{ Knowledge about women's reproductive age } \\
\hline No & 86 & 78.2 & 78.2 \\
\hline Yes & 24 & 21.8 & 100.0 \\
\hline Total & 110 & 100.0 & \\
\hline \multicolumn{4}{|c|}{ Knowledge abut STIs } \\
\hline No & 20 & 18.2 & 18.2 \\
\hline To some extent & 45 & 40.9 & 59.1 \\
\hline Yes & 45 & 40.9 & 100.0 \\
\hline Total & 110 & 100.0 & \\
\hline \multicolumn{4}{|c|}{ Knowledge about women becoming pregnant } \\
\hline No & 31 & 28.2 & 28.2 \\
\hline To some extent & 39 & 35.5 & 63.6 \\
\hline Yes & 40 & 36.4 & 100.0 \\
\hline
\end{tabular}




\begin{tabular}{|c|c|c|c|c|c|}
\hline Total & \multicolumn{2}{|l|}{110} & 100.0 & \multirow{2}{*}{\multicolumn{2}{|c|}{ Cumulative Percent }} \\
\hline Indicators & \multicolumn{2}{|c|}{\begin{tabular}{|l|l} 
Frequency & \\
\end{tabular}} & Percent & & \\
\hline \multicolumn{6}{|c|}{ Knowledge about women's reproductive age } \\
\hline No & \multicolumn{2}{|c|}{\begin{tabular}{l|l}
86 &
\end{tabular}} & 78.2 & & 78.2 \\
\hline Yes & \multirow{2}{*}{\multicolumn{2}{|c|}{24}} & 21.8 & & 100.0 \\
\hline Total & & & 100.0 & & \\
\hline \multicolumn{6}{|l|}{ Knowledge abut STIs } \\
\hline No & \multicolumn{2}{|l|}{20} & 18.2 & & 18.2 \\
\hline To some extent & \multicolumn{2}{|l|}{45} & 40.9 & & 59.1 \\
\hline Yes & \multicolumn{2}{|l|}{45} & 40.9 & & 100.0 \\
\hline Total & \multicolumn{2}{|c|}{\begin{tabular}{l|l}
110 \\
\end{tabular}} & 100.0 & & \\
\hline \multicolumn{6}{|c|}{ Knowledge about transmission routes of HIV/Aids } \\
\hline \multicolumn{2}{|l|}{ Not applicable } & \multicolumn{2}{|l|}{27} & 24.5 & 24.5 \\
\hline \multicolumn{2}{|c|}{$\begin{array}{l}\text { Sexual intercourse with infected } \\
\text { person }\end{array}$} & \multicolumn{2}{|l|}{16} & 14.5 & 39.1 \\
\hline From infected mother & baby & 3 & & .7 & 41.8 \\
\hline Blood transfusion & & 8 & & .3 & 49.1 \\
\hline $\begin{array}{l}\text { razors or blades use by } \\
\text { infected person }\end{array}$ & & 4 & & .6 & 52.7 \\
\hline All of the above & & 52 & & 7.3 & 100.0 \\
\hline Total & & 110 & & 0.0 & \\
\hline Knowledge about mea & of prevent & on fron & m STDs & & \\
\hline No & 55 & & 50.0 & & 50.0 \\
\hline To some extent & 31 & & 28.2 & & 78.2 \\
\hline Yes & 24 & & 21.8 & & 100.0 \\
\hline Total & 110 & & 100.0 & & \\
\hline FP knowledge & & & & & \\
\hline No & 3 & & 2.7 & & 2.7 \\
\hline To some extent & 20 & & 18.2 & & 20.9 \\
\hline Yes & 87 & & 79.1 & & 100.0 \\
\hline Total & 110 & & 100.0 & & \\
\hline $\begin{array}{l}\text { III. Discussion by resp } \\
\text { Discussion on sexual in }\end{array}$ & $\begin{array}{l}\text { ndents } \\
\text { ercourse }\end{array}$ & & & & \\
\hline No & 54 & & 49.1 & & 49.1 \\
\hline To some extent & 24 & & 21.8 & & 70.9 \\
\hline Yes & 32 & & 29.1 & & 100.0 \\
\hline Total & 110 & & 100.0 & & \\
\hline Discussion on contrace & tive use & & & & \\
\hline No & 51 & & 46.4 & & 46.4 \\
\hline To some extent & 25 & & 22.7 & & 69.1 \\
\hline
\end{tabular}




\begin{tabular}{|l|c|c|c|}
\hline Yes & 34 & 30.9 & 100.0 \\
\hline Total & 110 & 100.0 & \\
\hline Discussion on body changes & \multicolumn{1}{|l|}{} \\
\hline No & 15 & 13.6 & 13.6 \\
\hline To some extent & 34 & 30.9 & 44.5 \\
\hline Yes & 61 & 55.5 & 100.0 \\
\hline Total & 110 & 100.0 & \\
\hline Facing problems during adolescence \\
\hline No & 3 & 2.7 & 2.7 \\
\hline To some extent & 9 & 8.2 & 10.9 \\
\hline Yes & 98 & 89.1 & 100.0 \\
\hline Total & 110 & 100.0 & \\
\hline Indicators & Frequency & Percent & Cumulative Percent \\
\hline Appropriate age to inform about sexual health \\
\hline 12-14 years & 49 & 44.5 & 44.5 \\
\hline 15-16 years & 45 & 40.9 & 85.5 \\
\hline 17-19 years & 16 & 14.5 & 100.0 \\
\hline Total & 110 & 100.0 & \\
\hline Opinion for teaching about puberty \\
\hline To some extent & 9 & 8.2 & 8.2 \\
\hline Yes & 101 & 91.8 & 100.0 \\
\hline Total & 110 & 100.0 & \\
\hline
\end{tabular}

Ms. Kaneez Fatima Mamdani is Lecturer of the department of Sociology, Population Sciences and Criminology. She is being teaching since 2003. She has Masters Degree in Sociology and PGD in Statistics. She is also in the last stages of completing her $\mathrm{PhD}$ studies.

Ms. Munazza Madani is also Lecturer in the department of Sociology, Population Sciences and Criminology. She is being teaching since 2006. She has Masters Degree in Sociology and M.Phil degree in Special Education.

Ms. Sultana Shaheen has completed her masters in population Sciences (Evening programme) in 2008 with A-grade. Currently working on a research project. 